\title{
STRATEGI PERIKLANAN PADA BISNIS RETAIL
}

\author{
Veny Ari Sejati
}

\author{
Fakultas Ilmu Sosial dan Ekonomi Universitas Respati Yogyakarta. Jl. Laksda Adisucipto \\ Yogyakarta, No Hp. 0811302890 \\ Email: Veny_ari_sejati@yahoo.com
}

\begin{abstract}
This research aims to analyze the benefits of advertising strategy of Poundland. The method used is a qualitative approach because its ability to produce an in-depth description to obtain an authentic understanding of the experience of the people concerned. The study found that Poundland conducted intensive advertising by utilizing important moments such as Halloween, Christmas, Mother Day, etc using Internet media, social media, and e-mail sent 1-2 times per week. Poundland also employs other media such as word of mouth spread among students. Catalog is also used as the print media to reach the consumers. Poundland uses communication technology and take advantage of important moments for advertising strategy. This description can be a reference for retail businesses in Indonesia to pay attention to important events in Indonesia such as national moments and utilizing non-traditional communication technologies as an advertising strategy.
\end{abstract}

Key words: retail, advertising, words of mouth

\begin{abstract}
Abstrak
Penelitian ini bertujuan untuk menganalisis manfaat strategi iklan Pounland. Metode yang digunakan adalah pendekatan kualitatif karena kemampuannya menghasilkan uraian yang mendalam sehingga dapat memperoleh pemahaman yang otentik mengenai pengalaman orang-orang yang bersangkutan. Hasil penelitian menemukan bahwa strategi periklanan Poundland dilakukan secara intensif dengan memanfaatkan peristiwa-peristiwa penting seperti Halloween, Christmast, Mother day, dan lain-lain dengan menggunakan media internet, media sosial, dan e-mail yang dikirim dengan frekuensi 1-2 kali per minggu. Media lain seperti words of mouth berkembang di kalangan pelajar. Katalog juga digunakan sebagai media cetak untuk berhubungan dengan konsumen. Poundland mengikuti perkembangan teknologi komunikasi dan memanfaatkan peristiwa-peristiwa penting untuk strategi periklanan. Penjabaran ini bisa menjadi referensi pelaku usaha retail di Indonesia agar memerhatikan peristiwa-peristiwa penting di Indonesia seperti hari-hari besar nasional dan memanfaatkan teknologi komunikasi non-tradisional dalam strategi periklanan.
\end{abstract}

Kata Kunci : retail, advertising, words of mouth

\section{Pendahuluan}

Trend advertising kini mengalami perkembangan seiring berkembangnya teknologi komunikasi.Strategiadvertising konvensional menggunakan media cetak seperti Koran, majalah,; media luar ruang; door to door sudah mulai dikurangi dan bahkan ditinggalkan oleh pemasar / pelaku bisnis, dan salah satu alasan utamanya adalah menyesuaikan perkembangan lingkungan dimana saat ini telah memasuki era layar sentuh. Perusahaan tentu saja akan tertinggal apabila tidak ber-inovasi dan mengikuti perkembangan lingkungan.
Sebagai contoh, banyak sales yang menganggap dirinya paling mengetahui soal pasar sehingga tidak membutuhkan belajar perkembangan pemasaran. Seperti yang diungkapkan Hermawan kertajaya dalam New Wave Pemasaran, bahwa orang sales yang punya pandangan menganggap tidak membutuhkan belajar soal pemasaran biasanya tidak akan bisa mempertahankan kesuksesannya dalam jangka waktu lama. Lanskap berubah sangat cepat sehingga praktik yang membawanya ke puncak kesuksesannya tidak akan bisa lagi diterapkan alias usang (Kertajaya, 2008:247). Hal itu 


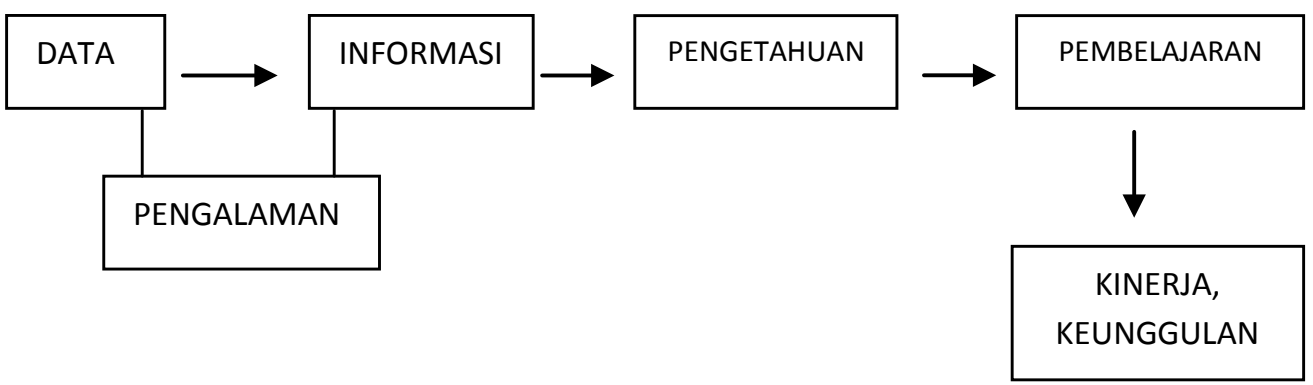

Gambar 1. Gambaran tentang Learning Society

diungkapkan juga oleh Rhenald Kasali dalam Myelin Mobilisasi Intangibles Menjadi Kekuatan Perubahan, bahwa semua pengalaman itu hanya akan berguna jika kita mampu mengubahnya menjadi pengetahuan, dan pengetahuan hanya dapat dimanfaatkan oleh orangorang yang mau belajar. (learning society), dan ditunjukkan pada gambar 1. (Kasali, 2010:228).

Dalam penelitian ini, obyek penelitian adalah Poundland yang berada di Western Street, Brighton, dimana merupakan retail yang menjual kebutuhan sehari-hari. Retail adalah perusahaan yang fungsi utamanya menjual produk kepada konsumen akhir untuk pemakaian pribadi dan rumah tangga. Ada empat fungsi retail, yaitu: (1) Membeli dan menyimpan barang, (2) Memindahkan hak milik barang tersebut kepada konsumen akhir,(3) Memberikan informasi mengenai sifat dasar dan pemakaian barang tersebut, (4) Memberikan kredit kepada konsumen (dalam kasus tertentu).

Retail tidak hanya menjual serangkaian brand, tetapi juga menjual dirinya sendiri sebagai tujuan untuk membeli produk. Konsumen mengambil keputusan kemana mereka berbelanja berdasarkan kualitas dari pengalaman belanja mereka, dan berdasarkan faktor -faktor retail seperti pilihan, seleksi dan layanan, hal itu pada gilirannya menjadi tujuan komunikasi pemasaran retail.

Pada umumnya para keluarga di
Brighton lebih senang berbelanja di Tesco dan Sainsburrys walaupun Poundland menawarkan harga lebih rendah daripada dua toko tersebut, hal tersebut dikarenakan Tesco mudah dijangkau masyarakat, lokasi toko seringkali di lingkungan pemukiman yang tidak dilewati transportasi umum dan tempat parkir disediakan langsung di depan toko. Demikian juga Sainsburrys, toko tersebut memasarkan produk fresh dengan tempat yang longgar, sehingga memberi kenyamanan pada konsumen yang sedang berbelanja. Poundland sangat terkenal lengkap produknya dan murah harganya di kalangan pelajar dan mahasiswa. Pelajar dari mulut ke mulut merekomondasikan kepada teman barunya untuk berbelanja di Poundland. Kedekatan pelajar dengan Poundland bahkan di upload melalui youtube : student life made essay!. Retail pesaing Poundland untuk kategori harga pada produk yang sama adalah $99 \mathrm{p}$ store. $99 \mathrm{p}$ store mempunyai strategi harga untuk semua barang yang dijual adalah 99 pence atau dibawah $£ 1$, sedangkan Poundland store membanderol harga $£ 1$ / lebih. Namun Poundland tidak pernah sepi konsumen dan deretan konsumen antri memenuhi kasir walaupun lokasi toko berdekatan. Selain itu berbagai macam hadiah yang ditawarkan di media sosial mendapat tanggapan positif dari pelanggannya dari negara Eropa. Hal tersebut merupakan salah satu indikasi bahwa strategi advertising yang digunakan Poundland 
cukup efektif pada konsumen atau negara dimana Poundland tersebar yang level perkembangan medianya bagus.

Penelitian ini diharapkan dapat digunakan sebagai tambahan ilmu pengetahuan bagi pelaku usaha retail di Indonesia tentang strategi advertising dimana saat ini perkembangan teknologi berada di era layar sentuh. Selain itu, penelitian ini diharapkan dapat memberi sumbangan ilmu pengetahuan baru di bidang komunikasi pemasaran.

\section{Metode Penelitian}

Penelitian ini menggunakan pendekatan kualitatif. Menurut Bogdan dan Taylor (Ruslan, 2003:213), penelitian kualitatif mampu menghasilkan suatu uraian yang mendalam tentang sikap, pandangan, ucapan, tulisan, dan tingkah laku yang memiliki aspek kejiwaan, yang dapat diamati, yang berasal dari kelompok, masyarakat, organisasi tertentu, dalamsuatu konteks setting tertentu, yang dikaji dari sudut pandang yang utuh, komprehensif dan holistic. Penelitian kualitatif bertujuan memperoleh pemahaman yang otentik mengenai pengalaman orang-orang, sebagaimana dirasakan oleh orang-orang yang bersangkutan tersebut (Mulyana, 2003:156).

Alat pengumpulan data dalam penelitian ini adalah observasi baik langsung maupun tidak langsung, di mana pengumpulan data melalui pengamatan dan pencatatan oleh pengumpul data terhadap gejala atau peristiwa yang diselidiki pada objek penelitian. Sifat observasi adalah tidak ada interaksi antara objek yang diamati dengan pengamat / pengumpul data. Kelebihan observasi yaitu data yang diperoleh up to date (terbaru) karena diperoleh dari keadaan yang terjadi pada saat itu (pada saat berlangsungnya peristiwa tersebut); Data lebih obyektif dan jujur karena obyek yang diteliti atau responden tidak dapat mempengaruhi pengumpul data (menutup kemungkinan manipulasi). Selain itu alat pengumpul data pendukung adalah dokumentasi dan wawancara jika terdapat data primer yang dianggap peneliti belum jelas.

Data diperoleh dari pengamatan langsung dan pencatatan-pencatatan pada saat dilokasi penelitian serta melalui digital media yang digunakan Poundland.

Model komponen analisis dalam penelitian ini meliputi reduksi data, sajian data, dan penarikan simpulan atau verifikasi, aktivitasnya dapat dilakukan dalam bentuk interaktif dengan proses pengumpulan data sebagai proses interaktif seperti yang disarankan oleh Miles \& Huberman (Sutopo, 1996:139).

\section{Hasil Penelitian dan Pembahasan}

Poundland Brighton berlokasi di Western Road, North Street, dan London road, dimana lokasi toko tersebut semua berada di lingkungan pusat perbelanjaan Churchill Square Brighton. Adapun kantor pusatPoundlandberlokasidiWillenhallWest Midlands, England. Poundland pertama kali berdiri pada tahun 1990 di Buton Upon Trent, menyediakan kebutuhan sehari-hari, perlengkapan sekolah dan perkantoran, perlengkapan pesta, perlengkapan perkebunan, perlengkapan hewan peliharaan, kosmetik, dan sebagainya, dengan harga $£ 1$ untuk hampir semua produk. Berdasarkan pengamatan langsung yang dilakukan oleh peneliti, terdapat juga produk dengan harga lebih dari $£ 1$ di toko yang berlogo padi melingkar pada shopsign warna hijau dan tagline "AMAZING VALUE" setiap advertisingnya dimana memiliki ribuan produk yang dipasarkan. Pada tahun 2014 terdapat 500 cabang Poundland di negara Eropa.

Dalam penelitianini, obyek penelitian adalah Poundland yang berlokasi di Western Road, Brighton, dimana terdapat fasilitas ATM dalam toko, lokasi parkir berdekatan dengan toko, buka pada hari 
Minggu, dan letak toko berada di pinggir jalan raya strategi di lingkungan pusat perbelanjaan. Selain itu, berdasarkan pengamatan peneliti, toko tersebut selalu ramai dikunjungi konsumen dari jam 08.30 hingga jam 18.00 sekalipun pada hari Minggu buka pada pukul 11.00.

Poundland merupakan salah satu retail terbesar di Eropa. Retail adalah perusahaan yang fungsi utamanya menjual produk kepada konsumen akhir untuk pemakaian pribadi dan rumah tangga. Menurut Sandra Moriarty dalam Advertising, dalam membidik konsumen, perhatian strategis pertama dari retail adalah wilayah geografi dimana konsumen tinggal, seberapa jauh naik kendaraan sampai ke toko, perhatian kedua adalah selera konsumen yang mungkin juga merefleksikan factor geografis. Ada tiga jenis toko retail, yaitu: 1 . Toko yang dimiliki sendiri. 2 . Toko yang menjadi bagian dari franchise. 3. Toko yang dimiliki oleh korporat besar

Tujuan retail merupakan tujuan dari komunikasi pemasaran retail, yaitu menaikkan store traffic (trafik toko), melalui advertising yang menawarkan potongan harga untuk produk populer dan mempromosikan citra produk dan pengalaman belanja (Moriarty, 2011 : 657). Berdasarkan pengamatan peneliti, tanpa menawarkan potongan hargapun Poundland telah memberikan harga murah dibandingkan retail lainnya seperti Tesco dan Sainsburrys, dan dalam mempromosikan citra produk, Poundland menyatakan: Big Brands Cost Less at Poundland di web sitenya. Bahkan pada tahun 2015 Poundland mendapatkan penghargaan Retail Industry Awards dalam kategari discount retailer setelah pada tahun 2014 meraih Grocer Gold Awards Winner Variety Discounter of the Year 2014.

\section{Strategi Advertising}

Advertising atau periklanan adalah jenis komunikasi pemasaran yang merupakan istilah umum dan mengacu kepada semua bentuk teknik komunikasi yang digunakan pemasar untuk menjangkau konsumennya dan menyampaikan pesannya (Moriarty, 2011:6). Banyak retail menggunakan setiap peristiwa untuk menaikkan penjualan dengan advertising. Seperti halnya Poundland, pada peristiwa tertentu seperti gardening day, mother day, christmast, tahun ajaran baru, halloween, dan national day lainnya, Poundland mengiklankan produk yang berhubungan dengan peristiwa-peristiwa tersebut ataupun national day melalui e-mail dan media sosial. Pesan-pesannya dikemas secara apik dan serentak di berbagai media yang digunakan.

Berdasarkan khalayak sasaran iklan, iklan Poundland digunakan untuk pengguna akhir (konsumen). Konsumen akhir adalah orang yang membeli barang untuk dikonsumsi bagi dirinya sendiri maupun orang lain, namun bukan untuk dijual maupun diproduksi kembali dalam bentuk produk lain (Widyatama, 2007:128). Hal tersebut dikarenakan Poundland merupakan retail dimana fungsi utamanya adalah menjual produk pada konsumen akhir.

Fungsi iklan menurut Alo Liliweri yaitu pemasaran, komunikasi, pendidikan, ekonomi, dan sosial (Widyatama, 2007 : 145).

Fungsi pemasaran, adalah fungsi yang diharapkan membantu pemasaran atau menjual produk. Artinya, iklan hanya digunakan untuk mempengaruhi khalayak agar mereka membeli dan mengkonsumsi produk. Dalam berbagai peristiwa, Poundland menggunakan peristiwa tersebut untuk mengiklankan produknya, misalnya pada saat gardening day dan mother day, Poundland akan mengirim e-mail dan memposting produk perlengkapan gardening dan berbagai kado beserta kartu dan pernik-perniknya 
untuk dipersembahkan pada saat mother day.

Fungsi komunikasi, yaitu iklan merupakan bentuk pesan dari komunikator kepada khalayaknya. Iklan merupakan pesan yang menghubungkan antara komunikator dengan komunikan. Poundland melalui e-mail yang dikirim rutin setiap 1-2x / minggu dan juga interaksi dengan komunikannya melalui media sosial merupakan kegiatan pemasaran yang menghubungkan Poundland dengan konsumen. Seringkali Poundland memberi pertanyaan atau berupa game dan disediakan hadiah seperti iPod, voucher, souvenir, bagi pemenang atau dianggap menjawab dengan tepat atau beruntung. Misalnya saat word book day, Poundland memberikan game berupa pertanyaan di media sosial dan e-mail seperti: happy world book day everyone, tell us which book character is most like you? And why. Semakin interaktif mediumnya dan semakin dekat dengan dialog, maka semakin personal dan persuasif pengalaman komunikasinya (Moriarty, 2011:360)

Fungsi pendidikan, yaitu mengandung makna bahwa iklan merupakan alat yang dapat membantu mendidik khalayak mengenai sesuatu, agar mengetahui dan mampu melakukan sesuatu. Poundland melalui iklannya: A) Mengingatkan adanya peristiwa penting atau national day, misalnya mother day, gardening day, world book day, easter day, dan lain-lain. B) Mengeduksi untuk selalu memberikan ucapan, misalnya: happy mother day pada tanggal 15 Maret, happy world book day. C) Saat gardening day, Poundland mengajak setiap orang membeli pot bunga dan perlengkapan berkebun untuk membersihkan dan memperindah kebun. Saat earth day, Poundland mengajak konsumen membeli produknya berupa lilin dan terdapat edukasi hemat energi dalam ungkapan : try to walk than drive, shop some candles and switch off your light.. happy earth day everyone yang dikirim melalui e-mail.

Fungsi ekonomi, mengandung makna bahwa iklan mampu menjadi penggerak ekonomi agar kegiatan ekonomi tetap dapat berjalan. Melalui iklan, masyarakat akan terbujuk untuk membeli barang dan melakukan konsumerisme yang akan membuat denyut perkonomian berkembang. Pada tahun 2015, Poundland untuk pertama kalinya turnover melampaui $£ 1$ billion dengan 500 cabang di negara Eropa. Harga produk di Poundland sangat murah dan seringkali memberi voucher ataupun hadiah-hadiah pada setiap pembelian dengan nominal tertentu yang yang diinformasikan melalui iklan, sehingga memicu konsumen untuk berbelanja. Selain itu, pada saat transaksi akan tercetak di struk pembayaran program hadiah dan voucher yang berlangsung, misalnya : get $£ 30$ off your first successful credit order at Very.co.uk when you spend $£ 60$ or more. Use promotional code 4QRCH before 28/02/15.

Fungsi sosial, yaitu membawa pengaruh dalam masyarakat misalnya memunculkan budaya konsumerisme, menciptkan status sosial yang baru, dan menciptakan budaya pop. Saatini terdapat jejaring sosial yang memungkinkan penggunanya mengekspresikan diri, berinteraksi, dan mempublikasikan konten sendiri di Internet. Poundland menggunakan jejaring sosial berupa facebook, google+, pinterest, youtube, twitter.

\section{Media Advertising}

Untuk menekan biaya tetapi menginginkan jangkauan yang luas bahkan diseluruh penjuru dunia, perusahaan seringkali menggunakan internet ataupun media sosial saat ini. Internet secara teknis adalah jaringan komputer international yang saling terhubung.

Kemunculan internet telah memperkaya platform media. Perusahaan telah 
menyadari bahwa orang muda mulai menjauhi media tradisional dan lebih banyak bermain game dan internet, seperti masuk jejaring sosial dan MySpace.com. Internet menimbulkan perubahan besar dalam operasi bsinis di beberapa peretail, seperti halnya Poundland. Hal tersebut tentu saja sangat efektif mengingat pada tahun 2014 sudah memiliki 500 cabang di Eropa. Bahkan pada akhir tahun 2015, Poundland telah mengumumkan melalui e-mail bahwa konsumen sudah bisa membeli secara on-line. Menurut Yearry Panji dalam Ilmu Komunikasi: sekarang dan tantangan masa depan, yang dikutip dari Frank Jefkins, Institut Praktisi Periklanan Inggris mendefinisikan periklanan sebagai pesan-pesan penjualan yang paling persuasive yang diarahkan kepada para calon pembeli yang paling potensial atas produk barang dan jasa tertentu dengan biaya semurahmurahnya (Budianto, Farid Hamid, 2011:470). Media elektronik seperti internet dan komunikasi nirkabel, telah mengubah lanskap media dan membuat bentuk komunikasi yang lebih dekat, interaktif dan personal.

\section{Website}

Website perusahaan seringkali disebut homepage atau dalam beberapa kasus adalah bisnis. Website www. Poundland.com digunakan Poundland untuk memuat produk, kategori produk, pencarian lokasi Poundland secara online. Selain itu, konsumen diarahkan untuk membuka www.poundland-questions. co.uk untuk mengetahui adanya hadiah dan voucher yang diselenggarkan pada bulan November 2014. Informasi tersebut dicetak pada struk pembayaran atau kwitansi pembayaran agar konsumen segera membuka website tersebut dan memberikan responnya. Disini proses komunikasi telah berlangsung dimana komunikator adalah Poundland membawakan pesan berupa program belanja, hadiah, voucher melalui media yaitu struk yang tercetak dan web site kepada pelanggannya, dalam hal ini adalah orang yang telah berbelanja di Poundland, dengan harapan mendapat respon dari pelanggannya tersebut. Proses komunikasi menurut Laswell adalah who (siapa yang mengatakan), says what (menyatakan kerja), in which channel (saluran apa), to whom (ditujukan kepada siapa), with what effect (pengaruh apa) (Suprapto. $2011: 8$ ).

\section{Advertising E-mail}

Poundland mengirim e-mail dari Poundlandltd@email.poundland. co.uk dengan frekuensi 1-2x / minggu untuk mengingatkan konsumen adanya national day atau peristiwa penting lainnya, mengarah pada produk yang dipasarkan, dengan slogan amazing value. Konsumen terlebih dahulu sign up untuk mendapatkan newsletter. Salah satu ciri atraktif dari advertising e-mail adalah biayanya cukup murah dan database membantu pemasar untuk membidik prospek dengan e-mail. Tingkat respon advertising e-mail menurut Sandra Moriarty sangat tinggi tetapi sayangnya tidak semua orang menerima e-mail tanpa ijin.

\section{Buzz atau Word Of Mouth}

Melalui pengamatan langsung yang dilakukan peneliti, Poundland merupakan salah satu retail terkenal dikalangan pelajar karena murah, lengkap, menyediakan makanan dan minuman halal, dan menyediakan voucher serta hadiah. Pelajar senior akan merekomondasikan Poundland kepada pelajar baru tentang kelebihan berbelanja di Poundland. Sebuah studi tahunan penggunaan media oleh perusahaan BIG terhadap 15.000 konsumen menemukan bahwa bentuk media yang paling berpengaruh adalah word of mouth. Salah satu factor paling penting dalam 
pengambilan keputusan konsumen ialah opini orang lain seperti keluarga dan teman (Moriarty, 2011 : 361).

\section{Media Sosial}

Poundland menggunakan media sosial berupa facebook, google+, pinterest @ poundlandwww.poundland.co.uk, instagram, you tube, twitter @poundland untuk berhubungan dengan konsumen. Media sosial seperti facebook dan twitter sangat intensive berinteraksi dengan konsumen dan memberikan game berupa pertanyaan atau pendapat tentang peristiwa penting yang akan terjadi, disediakan hadiah bagi comment yang dianggap tepat. Misalnya saat Halloween, Poundland akan membagikan voucher $£ 20$ bagi konsumen yang bisa menjawab melalui comment karakter Halloween dalam gambar yang disediakan. Poundland memberikan $£ 100$ bagi konsumen yang beruntung dengan like dan meng comment apa produk favorite dari Poundland pada saat merayakan pembukaan toko baru.

\section{Katalog}

Katalog merupakan salah salah satu media cetak yang digunakan Poundland, diletakkan di dalam rak antara pintu masuk dan kasir. Catalog berisi kategori produk, harga, dan peristiwa penting yang akan berlangsung, misalnya, 2 bulan menjelang natal catalog berisi berbagai produk perlengkapan natal beserta harga dan diselingi kata-kata indah untuknatal. Media cetak mempunyai kelebihan diantaranya awet, bisa dibaca berulang kali, dan bagus untuk perbandingan belanja.

\section{Simpulan}

Berdasarkan tujuan penelitian dan analisis yang penulis lakukan dapat diperoleh kesimpulan bahwa strategi advertising oleh Poundland dilakukan secara intensive dengan memanfaatkan peristiwa-peristiwa penting seperti Halloween, Christmast, Word book day, Mother day, Easter, father day, dll dengan menggunakan media internet, media social, dan e-mail yang dikirim dengan frekuensi 1-2x/minggu. Adapun media lain seperti words of mouth berkembang di kalangan pelajar bahwa Poundland menyediakan produk halal, lengkap, dan murah seperti slogannya Amazing Value. Katalog merupakan satu-satunya media cetak yang digunakan untuk berhubungan dengan konsumen dan disediakan di dalam toko.

Berdasarkan kesimpulan diatas, maka peneliti memberikan saran diantaranya bahwa perkembangan teknologi komunikasi berkembang pesat, Poundland mengikuti perkembangan tersebut dan memanfaatkan peristiwa-peristiwa penting untuk strategi advertising.

Banyak masyarakat Indonesia bekerja di bidang retail dan umumnya masih memanfaatkan words of mouth dan katalog sebagai media untuk berinteraksi dengan para konsumen. Diharapkan penelitian ini bermanfaat untuk pelaku usaha retail di Indonesia agar memperhatikan peristiwa-peristiwa penting di Indonesia seperti hari-hari besar nasional dan memanfaatkan teknologi komunikasi non-tradisional dalam strategi adverstisingnya.

\section{Daftar Pustaka}

Budianto, Heri, Farid Hamid. (2011) Ilmu Komunikasi, Sekarang dan Tantangan Masa Depan. Jakarta: Kencana Prenadamedia Group.

Kasali, Rhenald. (2010) Myelin Mobilisasi Intangibles Menjadi Kekuatan Perubahan. Jakarta: PT.Gramedia Pustaka Utama.

Kertajaya, Hermawan. (2009) New Wave Marketing. Jakarta: PT. Gramedia Pustaka Utama.

Moriarty, Sandra, dkk, advertising, edisi kedelapan, 2011, Kencana Prenada Media Group, Jakarta 
Mulyana, Deddy. (2003). Metodologi Penelitian Kualitatif : Paradigma Baru Ilmu Komunikasi dan Ilmu Sosial Lainnya. Bandung: PT. Remaja Rosdakarya.

Rusady. (2003). Manajemen Public Relation $\mathcal{E}$ Media Komunikasi Konsepsi dan Aplikasi. Bandung : Edisi Revisi, PT. Raja Grafindo.

Suprapto, Tommy. (2011). Pengantar Ilmu Komunikasi Dan Peran Manajemen Dalam Komunikasi. Jakarta: PT. Buku Seru.
Sutopo, H.B. (1996). Metode Penelitian Kualitalif DasarDasar Teoritis Dan Praktis. Surakarta: Pusat penelitian UNS.

Widyatama, Rendra. (2007). Pengantar Periklanan. Yogyakarta: PINUS.

Website

www.Poundland.co.uk 